\title{
BOUNDARY SCHWARZ INEQUALITIES ARISING FROM ROGOSINSKI'S LEMMA
}

\author{
PETER R. MERCER
}

Abstract. We consider some Schwarz and Carathéodory inequalities at the boundary, as consequences of a lemma due to Rogosinski.

Mathematics subject classification (2010): 30C80, 30 J99.

Keywords and phrases: Schwarz lemma, Rogosinski lemma.

\section{REFERENCES}

[1] R. P. Boas And H. P. Boas, Invitation to Complex Analysis, Math. Assoc. of America 2010.

[2] V. N. Dubinin, The Schwarz inequality on the boundary for functions regular in the disk, J. Math. Sci 122 (2004), 3623-3629.

[3] P. L. Duren, Univalent Functions, Springer-Verlag, New York \& Berlin, 1983.

[4] P. R. Mercer, Sharpened versions of the Schwarz lemma, J. Math. Analysis \& Appl. 205 (1997), $508-511$.

[5] B. N. ÖRneK, Carathéodory's inequality on the boundary, J. Korean Soc. Math. Educ. Ser. B Pure Appl. Math. 22 (2015), 169-178.

[6] B. N. ÖRNEK, The Carathéodory inequality on the boundary for holomorphic functions in the unit disk, J. Math. Physics, Analysis, Geometry 12 (2016), 287-301.

[7] B. N. ÖRNEK AND B. GÖK, Boundary Schwarz lemma for holomorphic functions, Filomat 31 (2017), $5553-5565$.

[8] R. Osserman, A sharp Schwarz inequality on the boundary, Proc. Amer. Math. Soc. 128 (2000), 3513-3517. 